\title{
Análisis de conectividad estructural cerebral en demencia frontotemporal, usando imágenes de resonancia de difusión
}

\author{
Luis Fernando Enriquez ${ }^{1,}$, Pablo Alexander Reyes ${ }^{2}$, Andrea del Pilar Rueda ${ }^{1}$ \\ ${ }^{1}$ Grupo de investigación BASPI. Facultad de Ingeniería. \\ Pontificia Universidad Javeriana, Bogotá, Colombia. \\ ${ }^{2}$ Departamento de Radiología e Imágenes Diagnósticas, \\ Hospital Universitario San Ignacio, Bogotá, Colombia
}

Recibido 3 de julio de 2019. Aceptado 27 de noviembre de 2019

\begin{abstract}
Resumen-La progresión de los déficits cognitivos en la demencia frontotemporal (DFT) se acompaña de deterioro de la sustancia blanca. El impacto de la pérdida neuronal en la conectividad de la red estructural en la DFT y sus variantes aún no se comprende de manera rigurosa. Se evaluó el potencial del análisis de conectividad estructural cerebral, a partir de imágenes de difusión (dMRI), en la identificación de alteraciones producidas por la DFT y sus variantes, y la relevancia para su diferenciación. Un total de 137 estudios de dMRI divididos en: 20 pacientes con demencia semántica (DS), 20 con afasia progresiva primaria (APP), 52 con variante comportamental (bvDFT) y 45 controles fueron investigados. La conectividad estructural se estimó para todo el cerebro. Se emplearon dos tipos de análisis: medidas topológicas por teoría de grafos y network-based statistic. La organización topológica en las 3 variantes se vio significativamente alterada respecto de los controles, en las medidas de fuerza de conexión, longitud de camino y eficiencia global. La bvDFT se caracterizó por una alteración preferencial interhemisférica centrada en la región frontal del lóbulo izquierdo. En la APP se detectaron pequeñas alteraciones en el giro frontal inferior. Mientras que los pacientes con DS mostraron una mayor extensión de redes alteradas, con desconexiones en el lóbulo temporal de ambos hemisferios. Las alteraciones globales de las redes estructurales sugieren un cambio en la eficiencia de intercambio de información, además de que la localización de dichos cambios se puede asociar con el progreso neuropatológico de la DFT.
\end{abstract}

Palabras clave-Biomarcadores, Conectividad estructural, Demencia frontotemporal, Imagen de difusión por resonancia magnética.

\% Dirección para correspondencia: Ifernando.enriquez@javeriana.edu.co

DOI: https://doi.org/10.24050/19099762.n25.2019.1332 


\title{
Cerebral STRUCTURAL CONNECTIVITY ANALYSIS IN FRONTOTEMPORAL DEMENTIA USING DIFFUSION RESONANCE IMAGING
}

\begin{abstract}
The progression of cognitive deficits in frontotemporal dementia (FTD) is accompanied by white matter deterioration. However, the impact of neuronal loss on the connectivity of the structural network in the FTD and its variants is not well understood yet. This study aimed to evaluate the potential of structural brain connectivity, in the identification of alterations and changes produced by the FTD and its variants, and the relevance of these measures for its differentiation. A total of 137 studies of dMRI divided as follows: 20 patients with semantic dementia (SD), 20 with progressive primary aphasia (PPA), 52 with behavioral variant (bvFDT) and 45 controls were part of the study. The structural connectivity derived from dMRI was estimated for the whole brain. Two types of analysis were executed: topological measures by graph theory and network-based statistic. Global topological organization in the 3 variants of FTD was significantly altered compared to controls, as seen in measures like connection strength, path length and global efficiency. The bvFTD was characterized by a preferential interhemispheric alteration focused on the frontal region of the left hemisphere. In the PPA a few alterations were detected in the inferior frontal gyrus. While patients with SD showed a greater extension of altered networks, due to high disconnections in the temporal lobe in both hemispheres. The global alterations of the structural networks suggest a change in the efficiency of information exchange between brain regions. Likewise, the location of these changes can be related with the neuropathological progress of the FTD.
\end{abstract}

Keywords-Biomarkers, structural connectivity, diffusion magnetic resonance imaging, frontotemporal dementia.

\section{ANÁLISE DA CONECTIVIDADE ESTRUTURAL CEREBRAL NA DEMÊNCIA FRONTOTEMPORAL, UTILIZANDO RESSONÂNCIA DE DIFUSÃO}

Resumo-A progressão dos déficits cognitivos na demência frontotemporal (DFT) é acompanhada pela deterioração da substância branca. O impacto da perda neuronal na conectividade da rede estrutural na DFT e suas variantes ainda não é rigorosamente compreendido. O potencial da análise da conectividade estrutural cerebral foi avaliado, a partir de imagens de difusão (dMRI), na identificação de alterações produzidas pelo DFT e suas variantes, e a relevância para sua diferenciação. Foram estudados 137 estudos de dMRI divididos em: 20 pacientes com demência semântica (SD), 20 com afasia progressiva primária (APP), 52 com variante comportamental (bvDFT) e 45 controles. A conectividade estrutural foi estimada para todo o cérebro. Dois tipos de análise foram utilizados: medidas topológicas pela teoria dos grafos e estatística baseada em rede. A organização topológica nas três variantes foi significativamente alterada em relação aos controles, nas medidas de força da conexão, comprimento do caminho e eficiência geral. O bvDFT foi caracterizado por uma alteração inter-hemisférica preferencial centrada na região frontal do lobo esquerdo. Na APP, pequenas alterações foram detectadas no giro frontal inferior. Enquanto os pacientes com SD apresentaram maior extensão de redes alteradas, com desconexões no lobo temporal de ambos os hemisférios. As alterações globais das redes estruturais sugerem uma alteração na eficiência da troca de informações, além do fato de que a localização dessas alterações pode estar associada ao progresso neuropatológico da DFT.

Palavras-chave-biomarcadores, conectividade estrutural, demência frontotemporal, imagem de difusão por ressonância magnética.

\section{INTRODUCCIÓN}

L a demencia frontotemporal (DFT) es un síndrome cerebral adquirido y hoy en día representa un importante problema de salud pública. La Organización Mundial de la Salud estima que las tasas de demencia se duplicarán cada 20 años, alcanzando más de 110 millones de casos a nivel mundial para 2050. Además, se espera que la DFT se convierta en el segundo subtipo de demencia más prevalente después de la enfermedad de Alzheimer (EA) [1]. La DFT abarca un conjunto de enfermedades que afectan los lóbulos frontal y temporal del cerebro. Estas regiones están involucradas, entre otras funciones, en la regulación del comportamiento (lóbulo frontal) y las habilidades lingüísticas (lóbulo temporal). El daño puede llevar a la reducción de las capacidades intelectuales y cambios en la personalidad, las emociones y el comportamiento [2, 3]. Dependiendo de qué manifestaciones clínicas muestran los sujetos, la DFT se puede clasificar en 3 subvariantes: variante de comportamiento (bvDFT), demencia semántica (DS) y afasia progresiva primaria (APP). En la bvDFT, los pacientes tienen problemas para regular su comportamiento en contextos sociales, incluida la desinhibición social, la impulsividad, la apatía y el aislamiento [4]"container-title":"Neurología (English Edition; Los pacientes con DS tienden a perder el significado de los conceptos [5]; y los pacientes con APP presentan discapacidad para generar el habla. 
Actualmente, un diagnóstico de DFT probable se basa en la evaluación de los síntomas clínicos, aunque existen presentaciones clínicas dispares, en ocasiones se superponen entre los trastornos neurodegenerativos, lo que dificulta un diagnóstico adecuado [6,7]. El diagrama de flujo de diagnóstico recomienda establecer una relación entre los síntomas y el proceso neurodegenerativo, el cual generalmente se determina mediante neuroimagen estructural o funcional [8]. Sin embargo, establecer diferencias entre los distintos tipos de demencia (como DFT y EA) a partir de la información y las medidas extraídas de la neuroimagen es un desafío, ya que hay muchas heterogeneidades y similitudes en cada uno. La resonancia magnética estructural (MRI) sigue siendo una herramienta central para el diagnóstico diferencial, sin embargo, se ha asociado con una sensibilidad subóptima en la evaluación inicial (hasta un 65 $\%)[9,10]$, principalmente porque se basa en un enfoque semicuantitativo, el cual busca la atrofia cortical y realiza una inspección visual por parte de los radiólogos. Mientras que, la imagen funcional es más sensible y, por lo tanto, se recomienda si la resonancia estructural parece normal.

En los últimos años, con la aparición de la resonancia magnética de difusión y la tractografía, se ha estudiado un enfoque alternativo. La técnica dMRI permite realizar estudios in-vivo y no invasivos, identificando patrones de alteraciones de la sustancia blanca en sujetos con DFT, que podrían ayudar a diferenciarla de otros tipos de demencia $[2,3,11]$. Mientras que la tractografía estima la probable orientación de la fibra a lo largo de las redes cerebrales, basadas en algunas métricas captadas por el modelo de difusión. Utilizando la dMRI varios estudios han demostrado que los parámetros de difusión se alteran en la sustancia blanca de los lóbulos temporal y frontal en pacientes con DFT en comparación con los controles o los sujetos con EA, estas alteraciones muestran ser más marcadas en las regiones anteriores que en las posteriores, como el fascículo uncinado, el segmento frontal del cuerpo calloso y el giro cingulado $[2,3,12,13]$. Incluso cuando la estimación de la orientación de los tractos de la materia blanca permite una evaluación de la integridad, generalmente esta se realiza en partes locales del cerebro, por lo que la comprensión del proceso neurodegenerativo subyacente se limita a las características anatómicas locales. Sin embargo, con el paradigma reciente de la conectómica, los estudios de dMRI proponen un mayor alcance, ya que el objetivo es utilizar las orientaciones estimadas de las tractos nerviosos, para caracterizar cuantitativamente las conexiones anatómicas entre diferentes regiones de la materia gris [14-16], permitiendo no solo describir conexiones específicas, sino también evaluar el daño causado por patologías cerebrales que alteran las conexiones nerviosas en los centros de actividad neuronal.
De hecho, estudios recientes han sugerido que la conectividad cerebral estructural puede estimarse a partir de algoritmos de tractografía y caracterizarse mediante el uso de enfoques topológicos, como la teoría de grafos [17, 18]. En este enfoque, el cerebro se puede representar como un conjunto de nodos unidos en pares por aristas. El análisis de grafos ha revelado características importantes de la organización del cerebro, como una arquitectura eficiente de "pequeño mundo" (que combina un alto nivel de segregación con un alto nivel de eficiencia global) y regiones de red altamente conectadas, denominadas "hubs" [19]. En relación con la DFT, la mayoría de los estudios han utilizado un acercamiento desde la conectividad funcional a través de la modalidad de resonancia magnética funcional para estudiar posibles alteraciones en las conexiones cerebrales de estos pacientes [19-22]. Esta técnica pretende mostrar redes cerebrales funcionalmente conectadas midiendo cambios sincronizados y dependientes del tiempo en los niveles de oxigenación de la sangre que perfunde el cerebro. Dichas investigaciones previas han reportado alteraciones topológicas de las redes, como reducción en la eficiencia global y en la conectividad interregional entre las regiones frontal, temporal, occipital, y subcortical, en pacientes de bvDFT en comparación con los controles [19, 21]. En cuanto a las variantes lingüísticas, los estudios respaldan una disminución de la conectividad en comparación con los controles, con afectaciones marcadas en el lóbulo temporal y una amplia gama de regiones corticales y en regiones de asociación visual y auditiva [20]. De esta manera el deterioro progresivo de los dominios cognitivos podría ser un reflejo de las alteraciones en la integridad funcional en los sistemas cerebrales. Sin embargo, pocos de ellos han explorado la conectividad entre subvariantes de DFT, y por lo general, los estudios emplean comparaciones entre pacientes con DFT o enfermedad de Alzheimer y un grupo de control.

Por otro lado, el enfoque estructural que se emplea con la ayuda de la dMRI trata de identificar conexiones "físicas" entre regiones cerebrales a partir de la reconstrucción de los tractos de sustancia blanca. No obstante, para nuestro conocimiento, en la demencia frontotemporal dicha conectividad estructural ha sido explorada en solo un estudio publicado [34], en el cual no se ha efectuado una comparación del comportamiento y/o cambios de las conexiones entre las subvariantes de este trastorno, dado que trabajo con pacientes que padecían demencia semántica y un grupo con Alzheimer. De igual manera, la mayoría de enfoques utilizados en el tratamiento de la información de dMRI para el estudio de las conexiones cerebrales se basa en las métricas de difusión derivadas de esta técnica (fracción anisotrópica, difusividad media), en los que la existencia de una conexión entre regiones, usualmente es definida por valores medios de estas magnitudes. En 
la presente investigación se pretende tomar una aproximación diferente para el tratamiento de la información captada por las imágenes de difusión, puesto que, es de interés obtener una idea de la probabilidad de proyección entre regiones cerebrales, y asimismo tratar de identificar cuáles de las conexiones reconstruidas son candidatas a mostrar alteraciones o daños en cada una de las variantes de la DFT.

En este orden de ideas, el objetivo de este estudio fue investigar la organización topológica en la conectividad estructural cerebral, en una cohorte de pacientes con demencia frontotemporal y controles, así como dentro de sus 3 variantes principales, utilizando el análisis por teoría de grafos de imágenes de resonancia magnética de difusión y los datos de tractografía. En esta evaluación, probamos las parcelaciones corticales del atlas Brainnetome, un enfoque de tractografía probabilística y varias medidas topológicas globales (relacionadas con la eficiencia de toda la red) para cuantificar e identificar qué información relevante derivada de la dMRI y el análisis de grafos podría ser útil para discriminar a los pacientes con DFT de los controles. Asimismo, intentamos encontrar y describir la alteración específica en las conexiones de cada variante comparando la conectividad estructural de todo el cerebro.

\section{Materiales y Métodos}

\section{Participantes}

Los estudios de resonancia magnética de noventa y dos pacientes (92) y cuarenta y cinco (45) controles se seleccionaron del repositorio de neuroimágenes de la clínica de memoria en el Hospital Universitario San Ignacio de la Universidad Javeriana. El grupo de pacientes con DFT se compuso con sujetos de las 3 variantes principales de esta demencia, de la siguiente manera: 52 de la variante comportamental (bvDFT), 20 con demencia semántica y 20 con afasia progresiva primaria (la Tabla 1 muestra los principales datos demográficos). Todos los pacientes tenían como idioma principal el español. Todos los pacientes fueron diagnosticados y clasificados en la clínica de memoria por un equipo multidisciplinario centrado en neurología, neuropsicología, geriatría y psiquiatría. Se excluyeron estudios en los que se registrase si los participantes tenían antecedentes de psiquiatría o enfermedad neurológica, abuso de sustancias y otras causas de daño cerebral.

\section{Imágenes de resonancia}

Las imágenes tomadas de la base de datos se obtuvieron utilizando un escáner Philips Achieva 3.0 T con una bobina SENSE de 16 canales. Como parte de un protocolo estandarizado, todos los sujetos tenían una secuencia de pulsos DTI de eco de disparo único con 32 gradientes de codificación de difusión y una imagen ponderada de no difusión: $\mathrm{B} 0=1000 \mathrm{~mm}^{2} / \mathrm{s}$, tiempo de repetición $[\mathrm{TR}]=$ $0,007 \mathrm{~s}$, tiempo de eco $[\mathrm{TE}]=0,086 \mathrm{~s}$, ángulo de giro $=$ $90^{\circ}$, matriz $=128 \times 128$, grosor de corte $=2 \mathrm{~mm}$. Además, se tomaron las imágenes estructurales $\mathrm{T} 1$ anatómicas y $3 \mathrm{D}$, las cuales habían sido adquiridas con los siguientes parámetros: tiempo de repetición $[\mathrm{TR}]=9,13 \mathrm{~s}$, tiempo de eco $[\mathrm{TE}]=0,003 \mathrm{~s}$, ángulo de giro $=8^{\circ}$, matriz $=220 \times 200$, con espesor de corte $=0,5 \mathrm{~mm}$.

\section{Análisis de los datos}

La línea general de procesamiento consistió en: un preprocesamiento inicial para la corrección de artefactos, seguido de la estimación del modelo de difusión, el registro del atlas al espacio de difusión, la tractografía, la generación de matrices de conectividad, para finalizar con los análisis de las medidas extraídas y las alteraciones de las conexiones. En la Fig. 1 se ilustra el flujo de trabajo de manera completa.

\section{Preprocesamiento y estimación del modelo de difusión}

El preprocesamiento se realizó con las herramientas disponibles en el software FSL [23]. Los primeros volúmenes de difusión se alinearon con el volumen b0 para corregir el movimiento de la cabeza. Luego, se usó BET (Brain Extraction Tool) para extraer una máscara cerebral con el fin de restringir todos los análisis (descartando cráneo y meninges). Más adelante, la distorsión inducida por la corriente de Foucault se corrigió utilizando la herramienta eddy correct. El modelo de difusión se estimó con BEDPOSTX, que representa una estimación bayesiana de los parámetros de difusión obtenidos mediante técnicas de muestreo. Este método permite modelar el entrecruzamiento de fibras dentro de cada vóxel del cerebro y crea distribuciones de probabilidad para los parámetros de difusión en cada vóxel. Simplemente cambiamos el número de fibras modeladas por vóxel a 2 y dejamos los otros parámetros por defecto de acuerdo con los lineamientos de FSL.

\section{Tractografia}

dMRI es una técnica no invasiva que se puede usar para monitorear el deterioro de la sustancia blanca $[2,10,12]$. La dMRI también ofrece la oportunidad de evaluar la orientación de los tractos, y esta característica se explota con algoritmos de tractografía para reconstruir las posibles vías de fibras nerviosas que conectan diferentes regiones del cerebro [16,24]. Por lo tanto, posibilita el mapeo de la arquitectura a un nivel de macroescala de conectividad cerebral. La tractografía probabilística se realizó en FSL utilizando PROBTRACKX. Esta herramienta toma muestras repetitivas de las distribuciones de direc- 
ciones de difusión principales en cada vóxel (obtenidas de BEDPOSTX), y en cada iteración estima la orientación a través de estas muestras locales para generar una "fibra probabilística".

\section{Análisis basado en regiones}

La conectividad estructural se estimó con un análisis basado en parcelaciones cerebrales. Las regiones de interés (ROI por sus siglas en inglés) o semillas se seleccionaron según el atlas de Brainnetome, el cual está conformado por 246 regiones [25]. La construcción de las matrices de conectividad se realizó utilizando el conjunto de regiones etiquetadas del atlas y un algoritmo de tractografía. PROBTRACKX permite calcular la matriz de conectividad, cuyos elementos $(i, j)$ representan el número de fibras (streamlines) que parten de la región $\mathrm{i}$, y terminan en la región j, es decir, se tiene un conteo de fibras entre pares de regiones cerebrales.

Para adaptar las etiquetas del atlas, las cuales se encuentran en el espacio de referencia de la plantilla MNI, las regiones etiquetadas del atlas se transformaron al espacio nativo de cada sujeto mediante un registro simétrico no lineal con las herramientas firt, fnirt e inwarp de FSL (siguiendo las recomendaciones estipuladas en https: //fsl.fmrib. ox.ac.uk/fsl/fslwiki/FNIRT/UserGuide) entre la imagen $\mathrm{T} 1$ del atlas y la imagen $\mathrm{T} 1$ de cada sujeto. Posteriormente, se halló la transformación desde el espacio estructural de cada paciente hacia el espacio de difusión. Las matrices de transformación resultantes, se combinaron en una sola, que permitiese registrar las etiquetas desde el espacio del atlas hacia espacio de difusión del sujeto de manera directa. En la Fig. 2 se muestra el esquema del registro descrito.

Tabla 1. Datos demográficos

\begin{tabular}{lllll}
\hline Grupo & bvDFT & DS & APP & Controles \\
\hline & $\Gamma(\mathrm{s})$ & $\Gamma(\mathrm{s})$ & $\Gamma(\mathrm{s})$ & $\Gamma(\mathrm{s})$ \\
Número (n) & 52 & 20 & 20 & 45 \\
Edad & $65,85(8,1)$ & $60,3(7,65)$ & $63,63(6,87)$ & $61,25(7,28)$ \\
Tiempo de enfermedad & $7,72(5,89)$ & $5,85(3,15)$ & $4,21(2,57)$ & -- \\
Años de educación & $12,92(4,66)$ & $12,3(5,85)$ & $11,62(6,32)$ & $14,4(5,13)$ \\
\hline
\end{tabular}

bvDFT: variante comportamental; DS: demencia semántica; APP: afasia progresiva primaria; $\Gamma$ : promedio muestral; s: desviación estándar muestral.

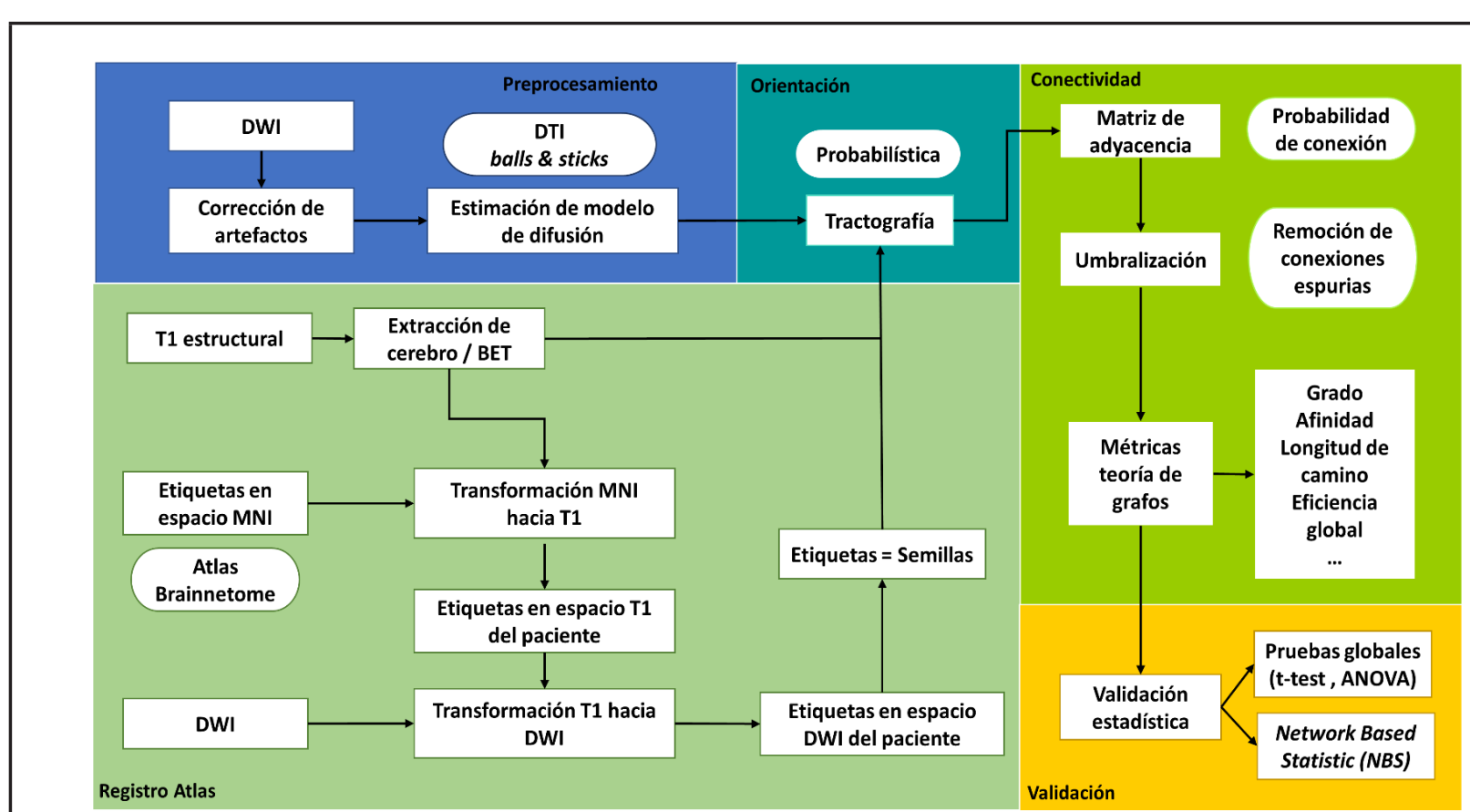

Fig. 1. Esquema completo del protocolo de procesamiento y análisis implementado sobre las imágenes de difusión (elaboración propia) 


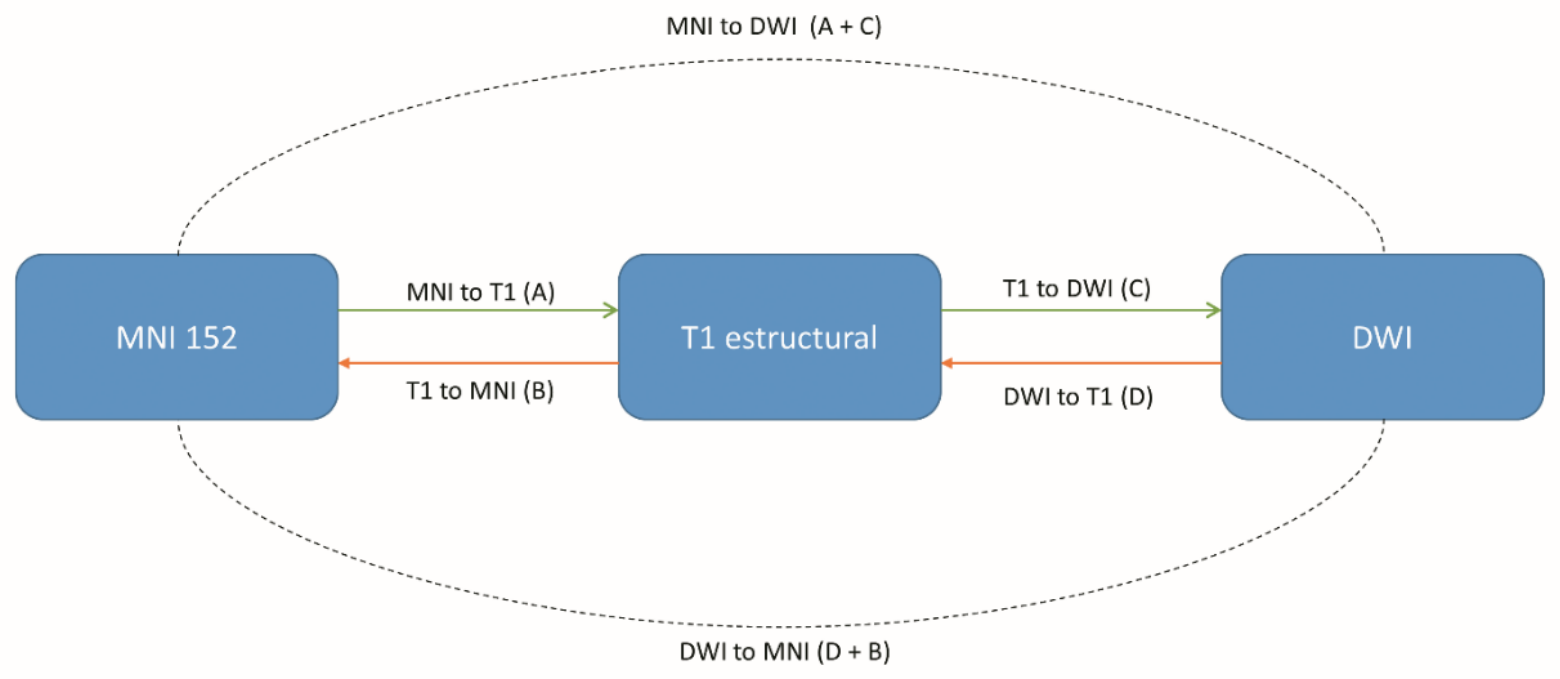

Fig. 2. Esquema de transformaciones realizadas. Para lograr el registro directo de MNI a DWI se requiere hallar en primer lugar, la transformación de MNI a T1, posteriormente la transformación de T1 a DWI, y por último combinarlas en un solo campo de deformación (elaboración propia). MNI 152: Espacio de referencia; DWI: espacio de difusión de cada sujeto.

\section{Análisis por teoría de grafos}

Un grafo está dado por un conjunto de nodos conectados por aristas que pueden ser no dirigidos o dirigidos y ponderados o no ponderados. Un grafo puede representarse mediante una matriz de adyacencia o conectividad, como la que se obtiene con los enfoques de tractografía. Las métricas escalares derivadas del análisis de grafos se pueden usar para caracterizar cuantitativamente la organización de redes y recientemente se ha encontrado que es útil para detectar alteraciones en poblaciones enfermas [26]. En Las matrices de adyacencia estimadas con FSL, los nodos corresponden a las etiquetas del atlas (ROI), y el peso de la conexión es el número de fibras que se trazan entre dos regiones corticales, que, una vez normalizados, estos pesos pueden interpretarse como una probabilidad de proyección entre parejas de regiones. Asimismo, partiendo de la premisa aceptada de que el cerebro no es una red totalmente conectada, y por tanto algunas de los elementos presentes en la matriz pueden representar conexiones falso-positivas $[27,28]$, se efectuó un paso de umbralización sobre estas, eliminando conexiones débiles y probablemente espurias entre las regiones cerebrales. La selección del umbral no es un proceso estandarizado y se describe en ocasiones como un parámetro subjetivo, puesto que, depende del interés particular de investigación, del tipo de imágenes usadas para la construcción de la matriz. Por lo tanto, para la selección de este se realizaron diversas pruebas con distintos valores de umbral en un rango entre $(0,01-0,25)$, en cada iteración se extrajeron las medidas topológicas buscando escoger un valor en el que se observase un comportamiento consistente en las magnitudes de las variables. De esta manera, los elementos cuya probabilidad de proyección fuese menor al $10 \%$ se colocaron en 0 (Se anexa como material suplementario la gráfica de medias mostrando el resultado de este barrido sobre las medidas extraídas). Igualmente, la selección del rango de análisis para el umbral es empírico, sin embargo, se tomó a consideración que analizar un amplio rango de umbrales generalmente oscurecerá los efectos que están presentes dentro de un régimen específico, mientras que elegir un rango que sea demasiado estrecho puede omitir los efectos que son evidentes en otros valores.

Las características topológicas de las redes, tales como, longitud de camino característica, la fuerza de conexión, el coeficiente de agrupamiento, la eficiencia global y la medida small - world se extrajeron utilizando la Brain Connectivity toolbox de Matlab. En estos grafos, la longitud de camino característica representa la ruta más corta promedio entre todos los pares de nodos en la red, y es una medida de integración funcional [27, 28]. La fuerza de conexión permite capturar variaciones en la magnitud de conectividad entre pares de regiones. La eficiencia global corresponde al inverso de longitud de camino más corta promedio y es una medida de la eficiencia general de transferencia de información a través de la red [27, 28]. El coeficiente de agrupamiento es una extensión de la interconectividad local y es equivalente a la fracción de vecinos del nodo que son vecinos entre sí. Las redes small-world 
se definen formalmente como redes que son significativamente más agrupadas que las redes aleatorias. Esto implica que tienen un alto coeficiente de agrupamiento indicando que los nodos tienden a formar regiones cíclicas, y por ende se caracterizan por una alta eficiencia en la transferencia y procesamiento de información [27, 28]. Varios estudios han revelado la tendencia hacia esta arquitectura de peuqeño mundo para el cerebro sano $[29,30]$.

Estas métricas se compararon entre los grupos mediante un análisis de varianza, seguidos de pruebas post - hoc mediante comparaciones múltiples $(\mathrm{p}<0.05)$. Los contrastes evaluados fueron: Controles vs DFT (bvDFT + APP + DS), Controles vs (APP+ DS), bvDFT vs (APP + DS), bvDFT vs APP y bvDFT vs DS.

\section{Análisis basado en redes (Network-Based Statistic)}

Se recurrió a las pruebas univariadas en masa (mass univariate tests) para explorar los cambios a nivel de las redes de los pacientes. Estos tipos de pruebas refieren al hecho de que una prueba estadística en particular (como una prueba $t$ ), se realiza de manera independiente en un gran número de nodos o aristas dentro de la red cerebral. Uno de los métodos para llevar a cabo este proceso es The Network-Based Statistic (NBS). NBS es un método estadístico no paramétrico para tratar el problema de comparaciones múltiples en un grafo. En NBS cada conexión está asociada con un estadístico de prueba y el valor $\mathrm{p}$ correspondiente, el objetivo es identificar grupos de conexiones (componentes conectados) que muestren un efecto significativo mientras se controla la probabilidad de cometer errores tipo I. Las estadísticas basadas en red se realizaron para examinar las diferencias de conectividad estructural regional en los componentes interconectados entre pacientes y controles en un nivel de significancia $\mathrm{p}$ $<0,05$. Los cálculos se basaron en una prueba t y 8,000 permutaciones y se realizaron en NBS toolbox de Matlab [31]. El valor p se corrigió por comparaciones múltiples. La visualización de los resultados de las redes de conectividad estructural alteradas se realizó con BrainNet Viewer [32]. Cabe aclarar que, en principio, el valor definido para $\alpha$ en la técnica NBS se hace de acuerdo con el tipo de efec- tos que se esperan en la red. Si se espera un efecto fuerte, pero restringido a un pequeño subconjunto de conexiones, se recomienda un umbral conservador (por ejemplo, eliminar todas las conexiones con $\mathrm{p}<0,001$ ), ya que dará como resultado componentes más pequeños. Por otro lado, como es el caso de nuestro estudio podríamos esperar que un efecto sea débil en conexiones individuales, pero que tenga una amplia distribución. En este caso, se recomienda usar un umbral menos conservador ( $\mathrm{p}$. Ej., $\mathrm{p}<0,05$ ). En cualquier caso, la ocurrencia de errores tipo I se controla, al nivel de los componentes conectados, independientemente del valor de significancia predefinida.

\section{REsUltados}

Se realizó un ANOVA para cada una de las métricas topológicas extraídas y mediante comparaciones múltiples se determinó que parejas de grupos presentaban diferencias estadísticamente significativas. En la Tabla 2 se resumen los resultados del análisis de varianza y en la Fig. 3 se condensan los resultados de las comparaciones múltiples para las métricas significativas, donde se resalta que grupo mostró una diferencia considerable en una determinada medida.

Se observa que los parámetros de longitud de camino característica y fuerza de conexión, son distintivos entre los sujetos control y las 3 variantes de DFT. La fuerza de conexión fue menor en los controles $(\Gamma=1,006, \mathrm{~s}=0,016)$ que en la bvDFT $(\Gamma=1,023, \mathrm{~s}=0,022)$, la DS $(\Gamma=1,026$, $\mathrm{s}=0,024)$ y la $\operatorname{APP}(\Gamma=1,032, \mathrm{~s}=0,024)$, mientras que la longitud de camino característica tuvo el comportamiento opuesto, siendo mayor en controles $(\Gamma=51,31, \mathrm{~s}=2,43)$ que en las 3 variantes de demencia $(50,24,49,61,49,74$ para bvDFT, DS y APP respectivamente). Por otro lado, las medidas de eficiencia global y small-world mostraron diferencias entre las variantes lingüísticas y los controles (rango para $p$ entre $0,015-0,025$ en Controles versus DS y p entre $0,008-0,015$ para Controles versus APP). Particularmente la fuerza de conexión presentó la diferencia más considerable entre las comparaciones entre controles y las variantes de DFT ( $\mathrm{p}<0,001$ para los 3 subtipos de demencia).

Tabla 2. ANOVA de una vía (un factor) y comparaciones múltiples

\begin{tabular}{cllllllllll}
\hline Métrica & \multicolumn{1}{c}{ Controles } & \multicolumn{1}{c}{ bvDFT } & \multicolumn{1}{c}{ APP } & DS & $\begin{array}{c}\text { p: Ctrl } \\
\text { vs } \\
\text { bvDFT }\end{array}$ & $\begin{array}{c}\text { p: Ctrl } \\
\text { vs APP }\end{array}$ & $\begin{array}{c}\text { p: Ctrl } \\
\text { vs DS }\end{array}$ & $\begin{array}{c}\text { p: } \\
\text { bvDFT } \\
\text { vs APP }\end{array}$ & $\begin{array}{c}\text { p: } \\
\text { bvDFT } \\
\text { vs DS }\end{array}$ & $\begin{array}{c}\text { p: } \\
\text { APP } \\
\text { vs DS }\end{array}$ \\
\hline LC & $51,31(1,71)$ & $50,24(2,43)$ & $49,74(1,84)$ & $49,61(2,27)$ & $\mathbf{0 , 0 4 7}$ & $\mathbf{0 , 0 1}$ & $\mathbf{0 , 0 1}$ & 0,78 & 0,73 & 0,99 \\
EG & $0,024(8,17 \mathrm{e}-4)$ & $0,025(0,001)$ & $0,025(9,42 \mathrm{e}-4)$ & $0,025(0,001)$ & 0,19 & $\mathbf{0 , 0 2}$ & $\mathbf{0 , 0 4}$ & 0,89 & 0,72 & 0,96 \\
SW & $1,56 \mathrm{e}-4(3,87 \mathrm{e}-5)$ & $1,46 \mathrm{e}-4(1,09 \mathrm{e}-4)$ & $1,69 \mathrm{e}-4(2,17 \mathrm{e}-5)$ & $1,82 \mathrm{e}-4(3,88 \mathrm{e}-5)$ & 0,6 & 0,16 & $\mathbf{0 , 0 4 9}$ & 0,97 & 0,98 & 0,56 \\
FC & $1,006(0,01)$ & $1,023(0,02)$ & $1,032(0,02)$ & $1,026(0,02)$ & $<\mathbf{0 , 0 0 1}$ & $<\mathbf{0 , 0 0 1}$ & $\mathbf{0 , 0 1}$ & 0,52 & 0,98 & 0,84 \\
CA & $0,008(9,66 \mathrm{e}-4)$ & $0,008(0,004)$ & $0,008(8,28 \mathrm{e}-4)$ & $0,0089(0,001)$ & 0,7 & 0,46 & 0,08 & 0,76 & 0,96 & 0,45 \\
\hline
\end{tabular}

Nota: LC: Longitud de camino característica; EG: Eficiencia global; SW: medida small-world; FC: Fuerza de conexión; CA: Coeficiente de agrupamiento; bvDFT: variante comportamental; APP: afasia progresiva primaria; DS: demencia semántica. 


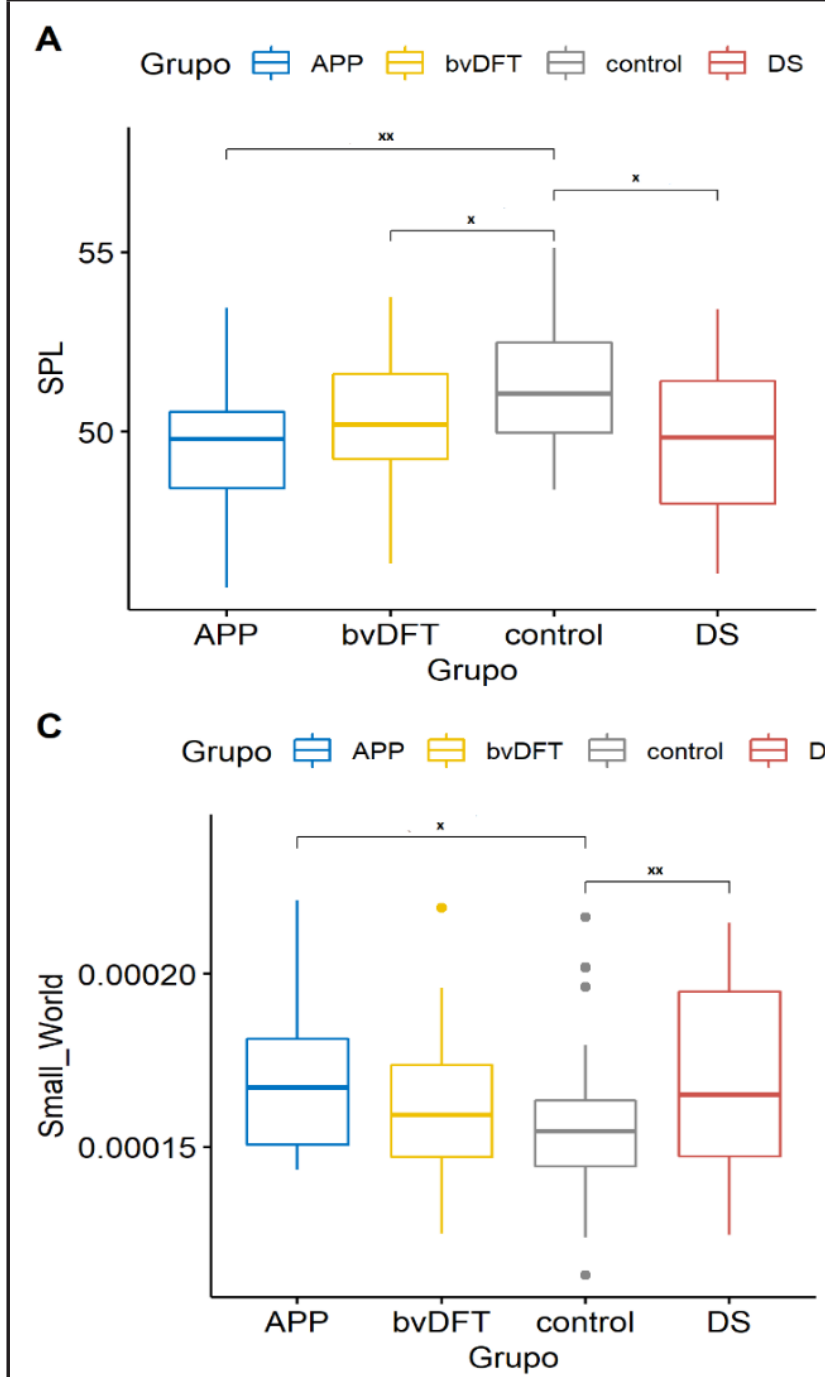

B Grupo 户 APP $户$ bvDFT $户$ control $户$ DS

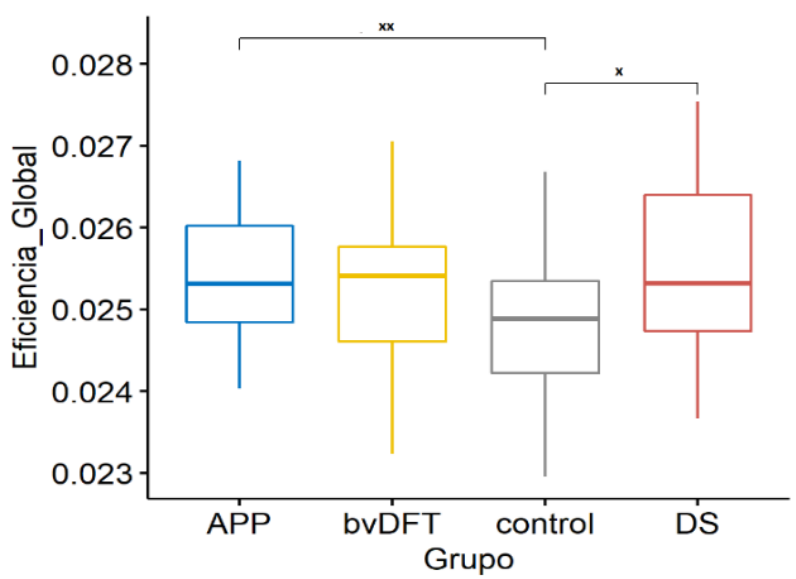

\section{D}

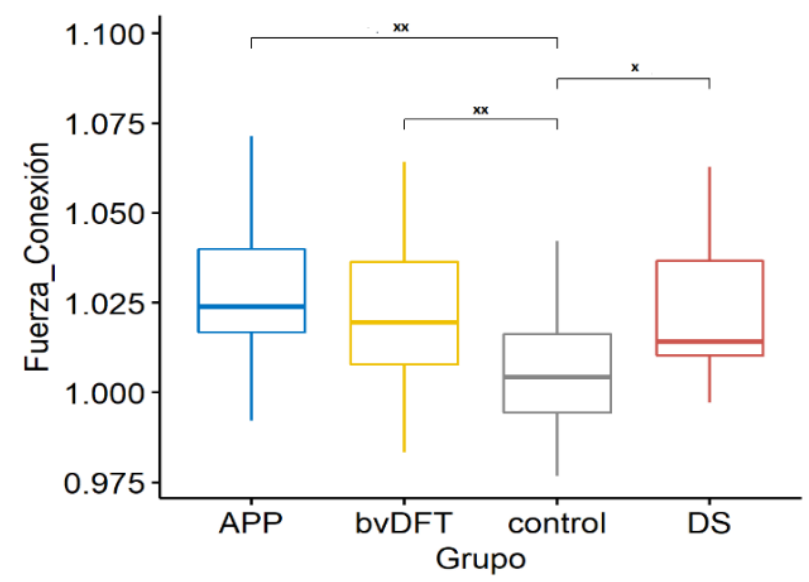

Fig. 3. Comparaciones múltiples entre métricas topológicas estadísticamente significativas. A: Longitud de camino característica; B: Eficiencia global; C: Medida small - world; D: Fuerza de conexión. * indica un valor $\mathrm{p}<0,05$; ** indica un valor $\mathrm{p}<0,001$

Adicionalmente, la medida de coeficiente de agrupamiento, si bien está muy cerca del límite de la significancia predefinida $(\mathrm{p}=0,08)$, esta indica una tendencia a revelar valores alterados entre controles y pacientes con demencia semántica.Por otro lado, las diferencias globales en los componentes interconectados de red entre pacientes y controles se examinaron con el método de Network-Based Statistic. Los resultados con este enfoque mostraron diferencias significativas entre los sujetos control y los grupos de bvDFT, DS, APP, (APP + DS) y (APP + DS + bvDFT). Igualmente, permitió la identificación de diferencias entre el grupo de la variante comportamental respecto al grupo de variantes lingüísticas combinado (DS + APP).

La primera comparación entre los controles y el grupo general de DFT (bvDFT + DS + APP) (Fig. 4a) indicó una extensa diferencia en las redes, con una alta proporción de nodos ubicados en los lóbulos frontales y temporales, en ambos hemisferios cerebrales. Los nodos con esta desconexión se localizaron principalmente en el giro frontal superior y medio, en el giro temporal superior e inferior. Asimismo, hubo diferencias marcadas en el giro insular, el giro cingulado, y estructuras subcorticales como la amígdala, el tálamo y los ganglios basales.

En cuanto al grupo control y la variante comportamental bvDFT (Fig.4b) las diferencias significativas se encontraron en redes con nodos predominantes en el hemisferio derecho en el lóbulo frontal y parietal (de acuerdo con las parcelaciones del atlas Brainnetome). Las alteraciones más marcadas fueron observadas en las regiones del giro frontal superior e inferior, el giro cingulado, el precúneo y el tálamo. 
$\mathbf{R}$

(a) Controles $>$ DFT
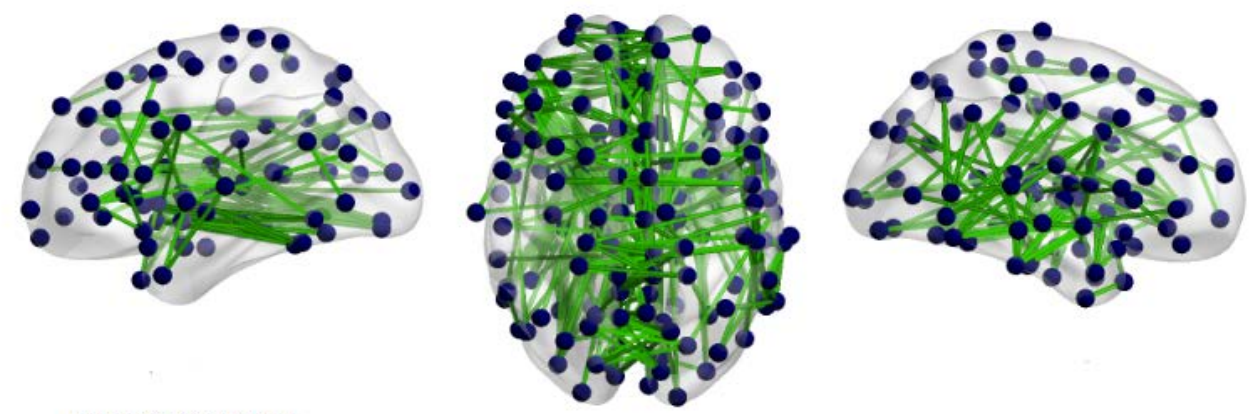

(b) Controles > bvDFT
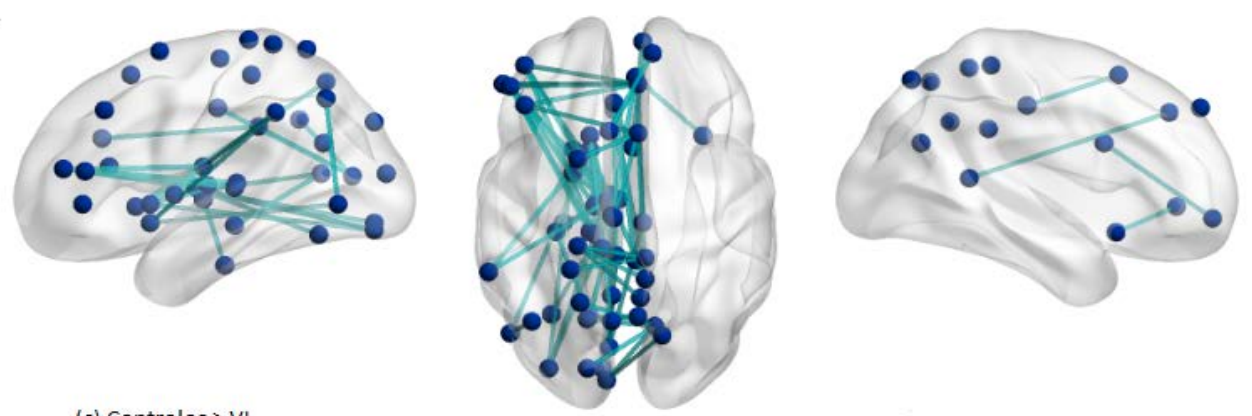

(c) Controles $>$ VL
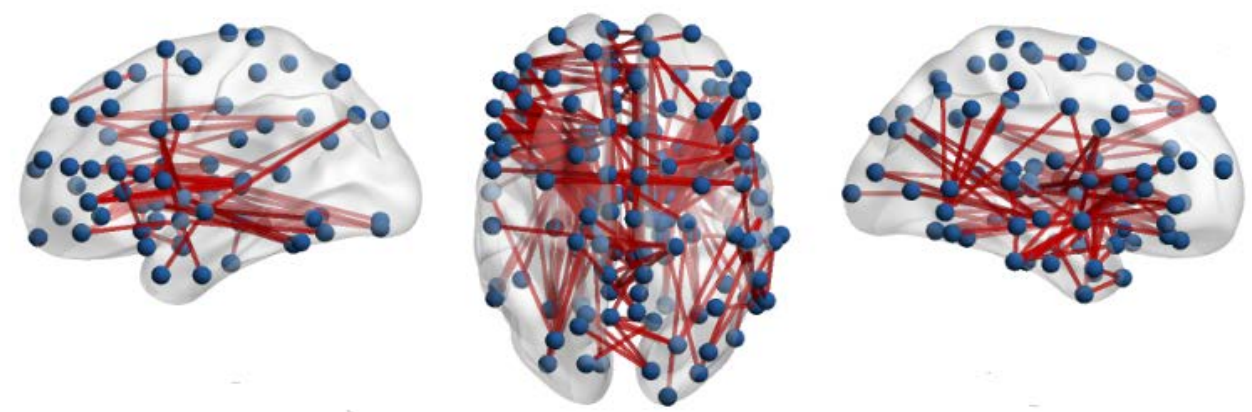

Fig. 4. Análisis basado en redes (NBS) entre controles y combinaciones de DFT. Las conexiones mostradas son aquellas que tienen la mayor probabilidad de estar alteradas respecto a los controles (como resultado de una prueba estadística t). Los puntos azules representan los nodos, correspondientes al centroide de cada parcelación cerebral, las aristas son las líneas que conectan pares de nodos, y son el resultado de una prueba $t$ entre grupos. a) Conexiones alteradas en el grupo de DFT general (combinación de las 3 variantes) respecto a los controles, la mayoría de las alteraciones se concentran en los lóbulos frontal y temporal de ambos hemisferios. b) Conexiones alteradas en la variante comportamental respecto al grupo control, hay una desconexión marcada en el lóbulo frontal del hemisferio derecho. c) Conexiones alteradas en las variantes lingüísticas (combinación de DS + APP) en comparación con los controles, la disminución de las conexiones se centró en el lóbulo frontal, y una asimetría en la alteración del lóbulo temporal, siendo más afectado el izquierdo; VL: Variantes lingüísticas

Respecto a las variantes lingüísticas, el contraste entre controles y la combinación de estas (DS + APP) mostró una alta afectación en ambos hemisferios. En el izquierdo, nodos de la porción temporal, en el giro temporal superior e inferior y del giro insular mostraron mayor desconexión, mientras que, en el hemisferio derecho, se observó una alta alteración el polo temporal medial. Adicionalmente, en ambos lados hubo diferencias en los ganglios basales, el tálamo, y el giro frontal (Fig. 4c).
Al separar la comparación entre controles y cada variante lingüística, los principales resultados indicaron que hubo más diferencias en los pacientes con demencia semántica que en aquellos con afasia progresiva primaria. Entre controles y la APP las redes afectadas solo se observaron en la región superior y media del giro frontal y en el giro cingulado (Fig. 5a). Mientras que el análisis entre sujetos sanos y la DS mostró diferencias principalmente en el lóbulo temporal y frontal, en zonas como el giro frontal 
superior e inferior derecho, el giro fusiforme derecho, además de regiones subcorticales como el putamen y el tálamo izquierdo (Fig. 5b).

El análisis entre variantes mostró diferencias entre la bvDFT y la combinación de las variantes lingüísticas (DS + APP) centradas en el hemisferio izquierdo, en regiones del giro frontal inferior, el giro orbital y la estructura subcortical del tálamo (en la porción de sus núcleos lateral prefrontal y premotor, Fig. 5c). No se encontraron diferencias entre la bvDFT y las variantes lingüísticas por separado, ni entre DS y APP.

Las diferencias aquí mencionadas se ilustran cuantitativamente en las Fig. 6 a 8, en las que se grafica la proporción de nodos afectados por macrorregión y por hemisferio para cada una de las comparaciones realizadas. Los macrorregiones son las estipuladas en el atlas Brainnetome, las cuales corresponden a 7 grandes porciones, 6 lóbulos y los núcleos subcorticales.
$\mathbf{R}$

(a) Controles > APP

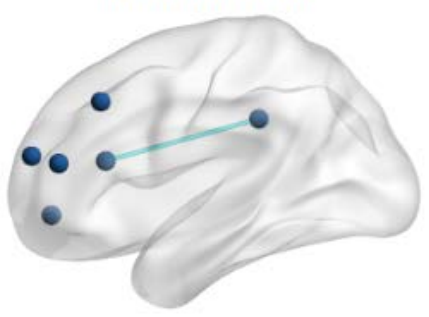

(b) Controles > DS

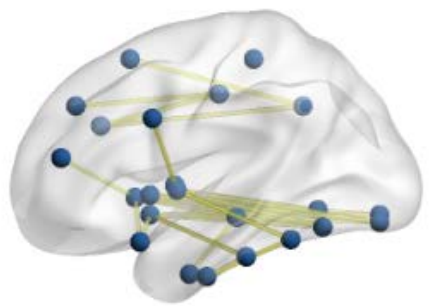

(c) bvDFT > VL

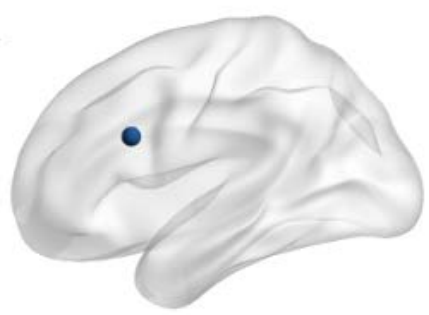

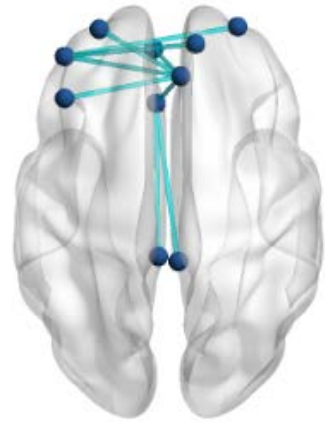
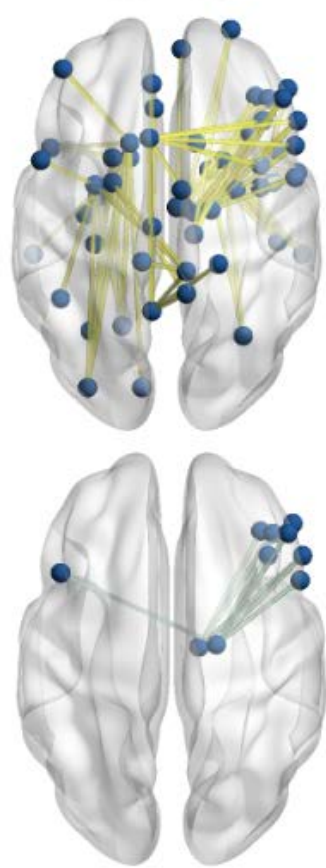

L
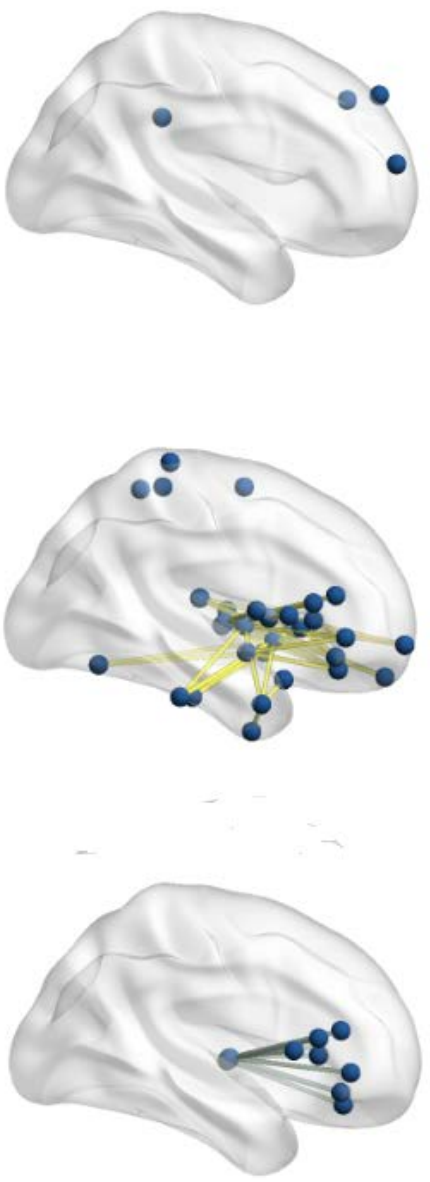

Fig. 5. Análisis basado en redes (NBS) entre controles y variantes lingüísticas por separado y entre variantes. Las conexiones mostradas son aquellas que tienen la mayor probabilidad de estar alteradas respecto a los controles (como resultado de una prueba estadística t). Los puntos azules representan los nodos, correspondientes al centroide de cada parcelación cerebral, las aristas son las líneas que conectan pares de nodos y son el resultado de una prueba t entre grupos. a) Conexiones afectadas en la afasia primaria progresiva respecto al grupo control, la desconexión se centró en el giro frontal y cingulado. b) Conexiones alteradas en la demencia semántica en comparación con los controles, se observa una desconexión más extensa y bilateral, centrada en el lóbulo temporal, particularmente en el giro temporal. c) Conexiones alteradas entre la variante comportamental y la combinación de las variantes lingüísticas (APP + DS), las pocas desconexiones se centran en el hemisferio izquierdo en la zona frontal y en los núcleos subcorticales, donde destaca perdida de conexiones en el tálamo; VL: Variantes lingüísticas 

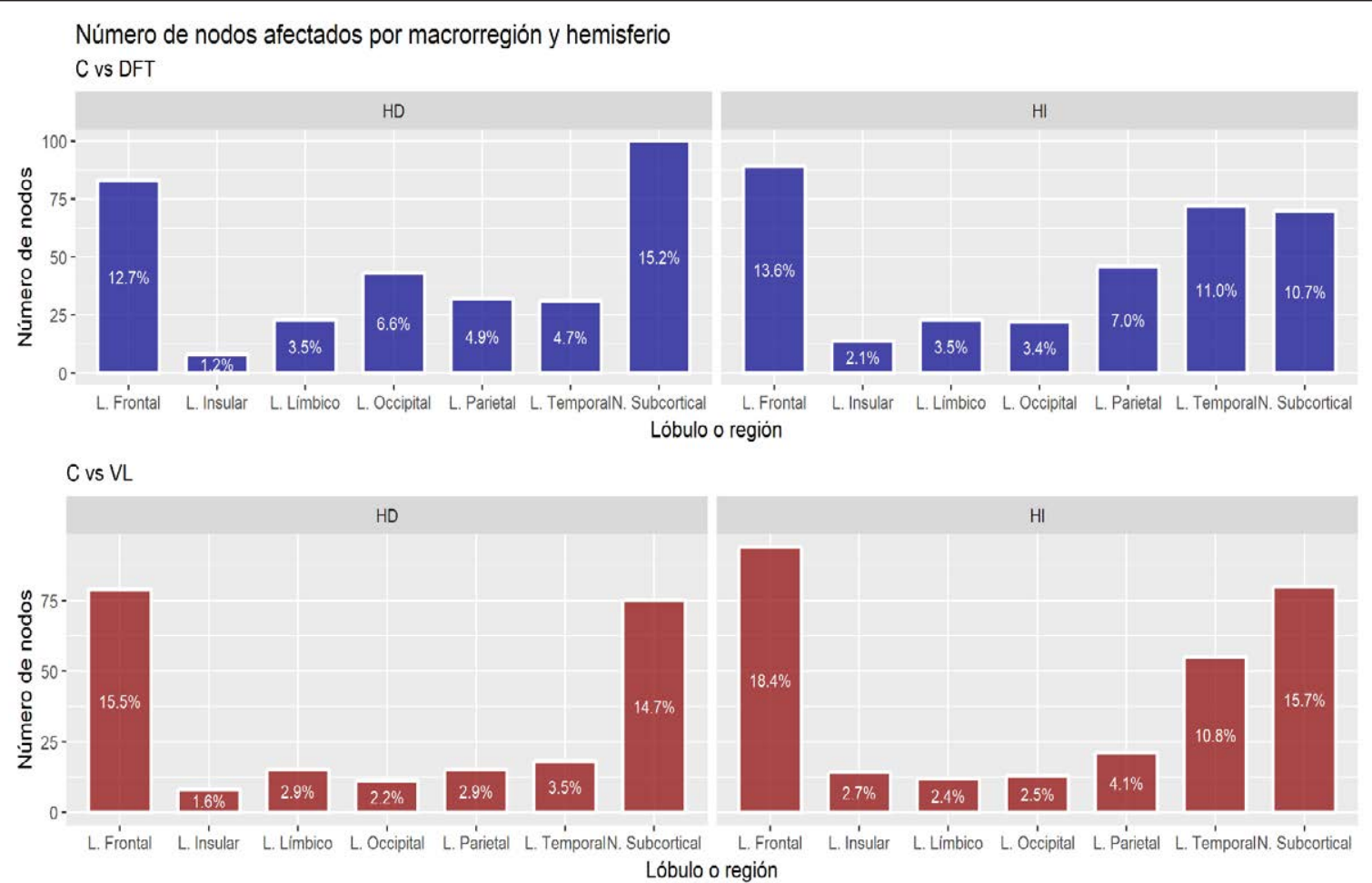

Fig. 6. Proporción de nodos alterados clasificados de acuerdo con su ubicación lobular y el hemisferio cerebral. a) Conexiones afectadas en controles vs DFT (bvDFT + APP + DS); b) Conexiones afectadas en controles vs variantes lingüísticas (APP + DS). En ambas comparaciones se observa una extensa alteración interhemisférica, con cambios predominantes en los lóbulos frontal, temporal y los núcleos subcorticales.

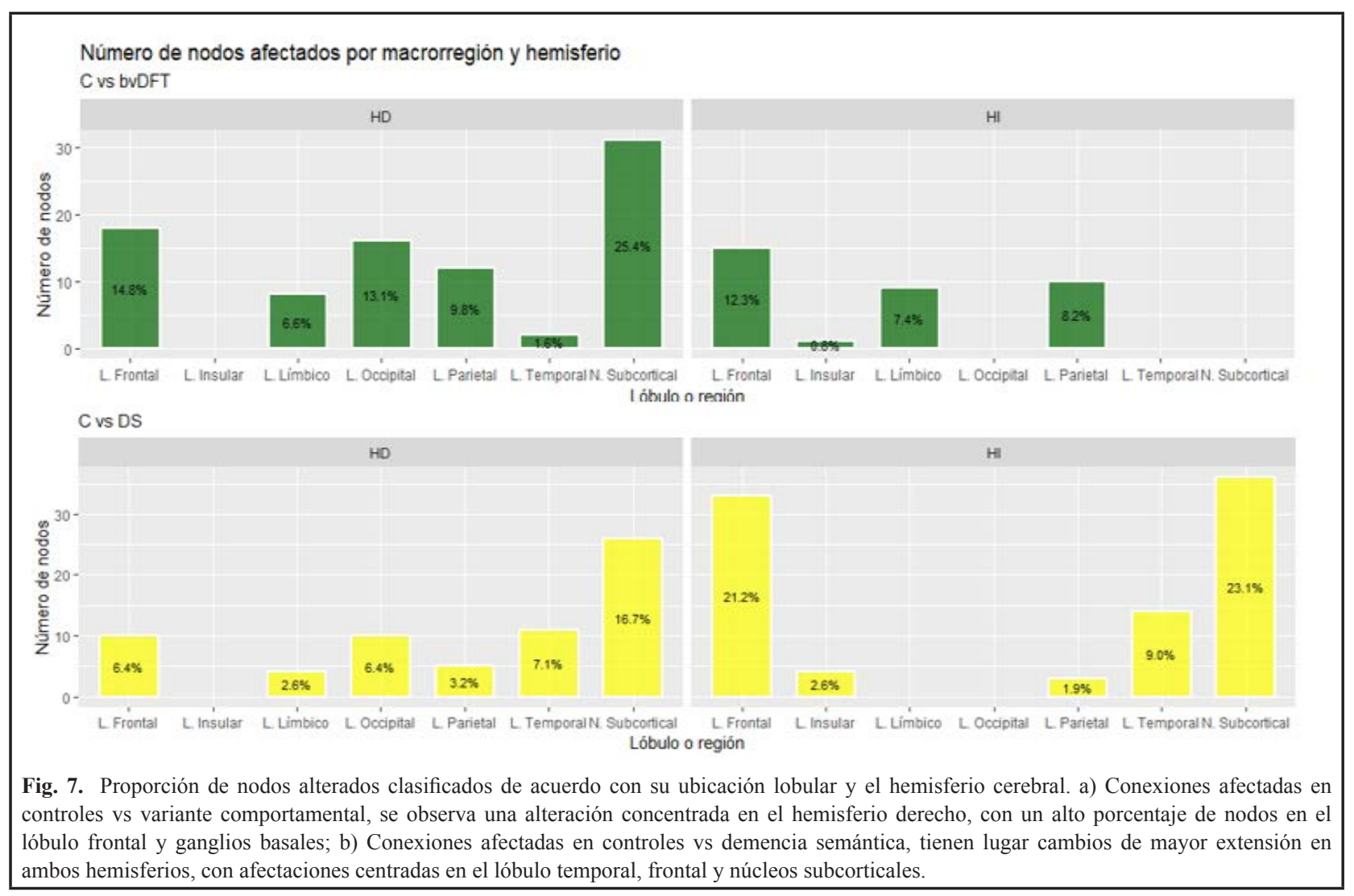




\section{Número de nodos afectados por macrorregión y hemisferio C vs APP}

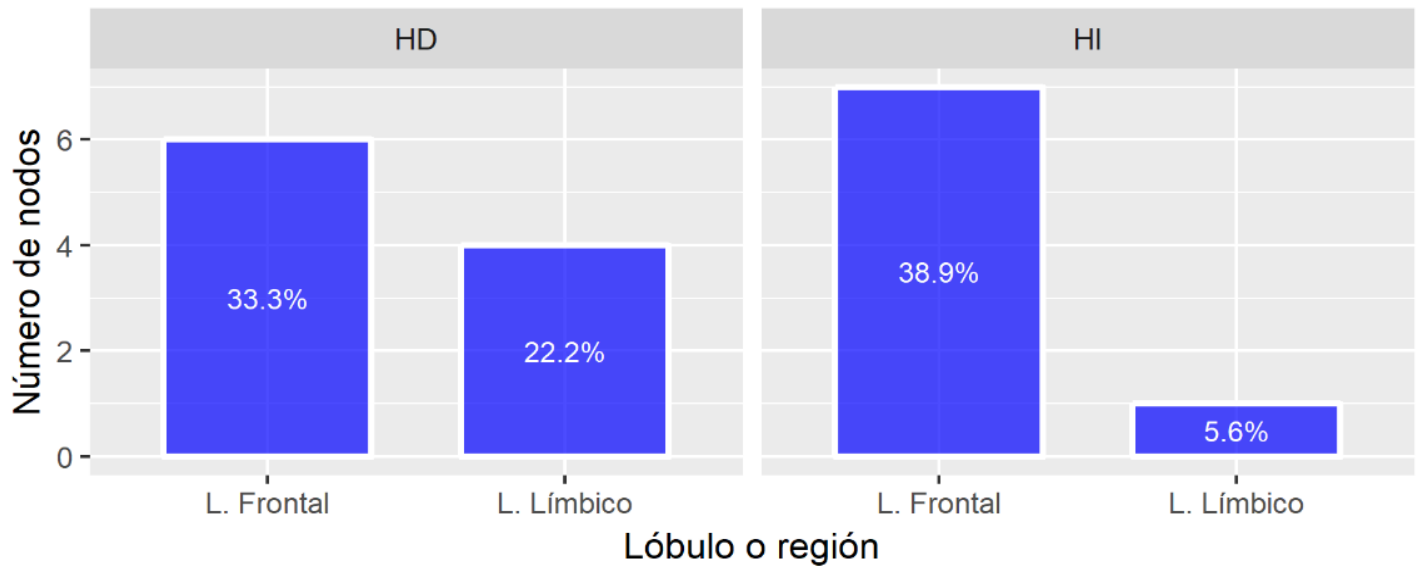

\section{bvDFt vs VL}

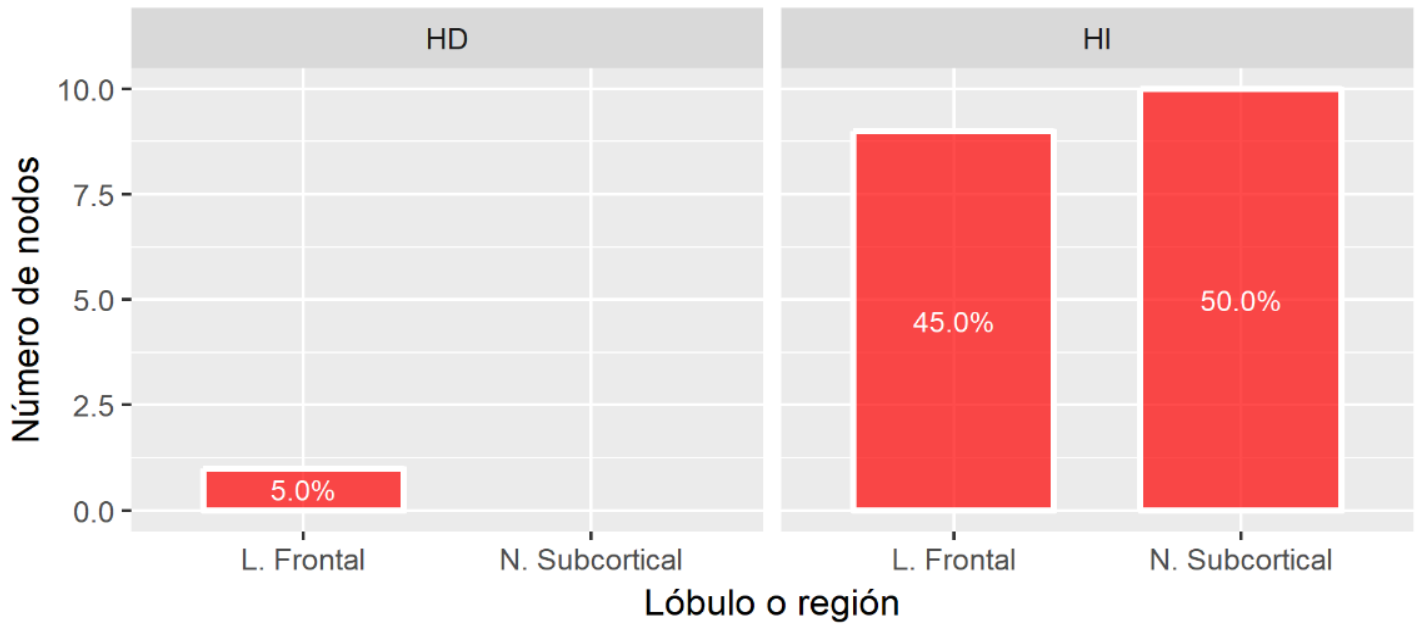

Fig. 8. Proporción de nodos alterados clasificados de acuerdo con su ubicación lobular y el hemisferio cerebral. a) Conexiones afectadas en controles vs afasia progresiva primaria, las alteraciones fueron observadas solamente en el lóbulo frontal y en el límbico, con una concentración un poco mayor en el hemisferio derecho; b) Conexiones afectadas en variante comportamental vs variantes lingüísticas (APP + DS), al combinarlas se observan cambios significativos intrahemisféricos en la región izquierda, que se extienden en el lóbulo frontal y los núcleos subcorticales.

Cabe mencionar que las desconexiones identificadas en cada comparación de grupos, se plantean ser significativamente diferentes, desde un punto estadístico. El método NBS aplica las denominadas pruebas univariadas en masa, al embeber las pruebas de hipótesis individuales que se efectúan sobre cada una de las conexiones de la red. En nuestro caso se definió una probabilidad de cometer conclusiones falso-positivas (denominado error tipo I) de 5 $\%(\alpha=0,05)$. De manera, que las conexiones alteradas son aquellas en las que se rechazó la hipótesis nula de igualdad entre grupos, $\mathrm{y}$, por ende, se les asocia una alta probabilidad de que realmente representen un resultado verdadero, particularmente con un nivel de confianza del $95 \%$.

\section{Discusiòn}

El enfoque de análisis de grafos y la conectómica en la exploración de la conectividad estructural cerebral, exhibe potencial para la evaluación de alteraciones en la organización topológica de las redes en pacientes con DFT y dentro de sus variantes. En el presente estudio se observa una contribución para el entendimiento de las afectaciones en las redes cerebrales y las métricas topológicas. La perspectiva basada en el análisis de las redes (NBS) mostró una mejor precisión en la detección de diferencias que el enfoque de métricas de teoría de grafos.

Los principales hallazgos muestran que la organización topológica de las redes estructurales está significativa- 
mente alterada en pacientes con DFT en sus 3 variantes principales. Las métricas topológicas de longitud de camino característica, fuerza de conexión, fueron útiles en la discriminación de los pacientes con bvDFT, DS y APP respecto de los controles, mientras que la eficiencia global y small - world mostraron potencial para la diferenciación de las variantes lingüísticas de la DFT (DS y APP) respecto a los sujetos control.

Estudios recientes han reportado resultados semejantes, como el de Agosta et al [19] y Filippi et al [33], en los cuales se compararon los pacientes con la variante comportamental respecto a controles. Estos mostraron afectaciones en la eficiencia global, longitud de camino característica y la fuerza de conexión, sugiriendo un decremento en la eficiencia en el intercambio de información entre regiones distantes y cercanas (desde el punto de vista topológico). Asimismo, en el estudio realizado por Reyes et al [20], en el que se empleó muestras de las 3 variantes de DFT, se determinó que medidas como la eficiencia global y la longitud de camino característica tenían potencial para la discriminación entre variantes lingüísticas, además de mostrar una correlación con el progreso de la enfermedad.

Lo anterior también fue soportado por lo hallado en la investigación de Andreotti et al [34], en el cual se recurrió a la modalidad de imágenes de resonancia de difusión para conectividad estructural. En este estudio se encontró que las medidas de LC, EG, FC resultaron afectadas en la variante de demencia semántica respecto de los sujetos sanos y mostraron ser similares a las de pacientes con enfermedad de Alzheimer. Si bien, la mayoría de las investigaciones en mención que apoyan los resultados encontrados, son de una modalidad distinta (resonancia magnética funcional), y a diferencia de nuestro enfoque la conectividad es funcional, se observa un común denominador en la tendencia a identificar alteraciones en medidas derivadas de la teoría de grafos. Este patrón de anormalidades en estas métricas sugiere su utilidad como elemento cuantitativo que complemente la discriminación de la DFT.

Aunque el uso de la conectividad estructural para el análisis de este tipo de pacientes aún se encuentra en crecimiento, resultados similares fueron reportados en un estudio reciente que empleo este enfoque de conectividad (Reyes PA. Biomarkers based on neuroimages to neurodegenerative diseases [Doctoral thesis]. Bogota D.C: Pontificia Universidad Javeriana; 184 p. Forthcoming 2019). En dicha investigación se encontró que las medidas de eficiencia global, longitud de camino y small-world fueron discriminantes entre las variantes lingüísticas y controles. Sin embargo, a diferencia de nuestro caso dichas métricas presentaron una magnitud menor en los pacientes con DS y APP que en controles (excepto por la longitud de camino característica). En el presente estudio, la dirección de las alteraciones encontradas en la organización topológica muestra una tendencia en las variantes de demencia a tener una estructura más regular. Este fenómeno podría interpretarse como una desviación de la arquitectura de red de "pequeño mundo", presumiblemente óptima y equilibrada que se ha caracterizado en sujetos sanos [29]. Aun cuando la direccionalidad de nuestros hallazgos es contraria a lo encontrado en el estudio de Reyes PA., estos han sido reportados previamente [35], donde sorpresivamente, los pacientes con DFT muestran cambios hacia una estructura de red quizás excesivamente más "ordenada".

El comportamiento opuesto en la direccionalidad de los resultados entre estudios puede deberse a las herramientas computacionales usadas durante el procesamiento. $\mathrm{Si}$ bien, las líneas de procesamiento empleadas son similares a la expuesta en la Fig. 1, los insumos y aproximaciones utilizadas varían en ciertas etapas. En efecto, las principales diferencias suelen corresponder al software empleado para la estimación del modelo de difusión, el algoritmo para la construcción de la tractografía y las matrices de conectividad, y la conformación de estas. Como se describió en la sección de metodología, en el presente estudio solamente se utilizó FSL para la consecución de dichas tareas, en cambio, en la investigación de (Reyes PA. Biomarkers based on neuroimages to neurodegenerative diseases [Doctoral thesis]. Bogota D.C: Pontificia Universidad Javeriana; 184 p. Forthcoming 2019) se empleó una combinación de herramientas y software (FSL, CAMINO, ANTs) para la estimación del modelo de difusión y la construcción de las matrices. Las matrices generadas en dicho estudio son simétricas y sus conexiones indican un valor asociado a parámetros de difusión, como la fracción anisotrópica o a la difusividad media entre pares de regiones. En contraste, las obtenidas con probtrackx en FSL son matrices asimétricas cuyos elementos representan un conteo de fibras entre las regiones semilla, y que luego de normalizarlas pueden entenderse como una probabilidad de proyección. Teniendo en cuenta que, el análisis topológico mediante teoría de grafos se da a partir de dichas matrices, las diferencias observadas sugieren que la direccionalidad de las métricas y análisis posteriores puede verse afectada por las técnicas, herramientas y aproximaciones realizadas durante la etapa de preprocesamiento. No obstante, en la actualidad no se ha definido un gold standard para la metodología de procesamiento para el análisis de conectividad ya sea funcional o estructural.

Aun con estas diferencias en los abordajes para el tratamiento de las imágenes, los diferentes resultados de los estudios son coherentes y se encaminan a mostrar alteraciones sobre métricas topológicas. No obstante, una limitación de estas medidas está asociada con la dificultad para establecer relaciones anatómicas entre la salida, es 
decir, los valores de estas medidas y las regiones o redes específicas que están siendo afectadas.

Con el fin de afrontar la restricción intrínseca de las métricas basadas en la topología, en este estudio el análisis alternativo mediante NBS permitió identificar redes y conexiones específicas alteradas por la demencia. En este estudio la variante comportamental bvDFT tuvo una desconexión bilateral con mayor tendencia hacia regiones ubicadas en el hemisferio izquierdo. Esta asimetría ya se ha reportado en estudios previos, en los que se evidencia desconexión alta de la porción frontoparietal [20, 33, 36 respecto a los controles, e incluso un deterioro en la región temporal respecto a pacientes con enfermedad de Alzheimer [37]. Los resultados mostraron ser congruentes con los modelos de neurodegeneración en DFT asociados a daños en las conexiones frontales [38, 39], por ejemplo, la pérdida de conectividad observada en la región del giro frontal superior, medio e inferior de los pacientes con bvDFT. Estas áreas y sus conexiones están relacionadas con la cognición social, la memoria y la inhibición. De manera similar, nuestros resultados mostraron alteraciones entre la región frontal y la zona límbica, especialmente en el giro cingulado, esta alteración ha sido reportada previamente $[20,40]$. La afectación de la región límbica puede asociarse con la interrupción entre los sistemas cerebrales afectivos $[33,40]$ using resting state (RS. Además de que el giro cingulado ha sido asociado con la motivación y el control del comportamiento [41].

En cuanto a las variantes lingüísticas los resultados sustentan un decremento en la conectividad en este tipo de pacientes respecto a los controles. En nuestro caso, los sujetos con DS exhibieron una mayor pérdida de conectividad que los pacientes con APP. La variante semántica mostró una desconexión extensa en ambos hemisferios, con una marcada alteración en la región temporal, la cual está asociada con la tarea de asignación de conceptos y el conocimiento. Igualmente, hubo una pérdida de conexiones en regiones subcorticales de los ganglios basales, estructuras que han sido relacionada con el aprendizaje procedimental y la memoria, además de participar en la comprensión de estímulos auditivos como los propios del lenguaje, la producción del habla y proceso sintáctico [42, 43]. Por su parte las pocas alteraciones detectadas de la afasia progresiva primaria se centraron en la región frontal, en el giro frontal superior e inferior, del cual se han identificado funciones del reconocimiento visual o gráfico de las palabras durante el proceso de lectura.

En el presente estudio las diferencias entre variantes solo fueron identificadas entre la bvDFT y la combinación de (DS + APP), en la que las regiones altamente afectadas fueron el giro frontal inferior y el tálamo. Se ha reportado previamente $[42,44]$ que la porción inferior del giro frontal se relaciona con el procesamiento gramatical y el reconocimiento de las palabras. Asimismo, el tálamo se ha descrito como una estructura de relevo de la información aferente de datos sensoriales (auditivos y visuales), que facilita la integración de esta y la transduce a información de mayor complejidad que contempla un significado para nosotros.

En conjunto, el enfoque de medidas topológicas globales de la red como la longitud de camino característica, fuerza de conexión, eficiencia global y small - world mostraron su potencial para la discriminación de sujetos sanos respecto a las variantes de demencia frontotemporal, al menos desde un punto de vista estadístico. Estos resultados mostraron ser congruentes con estudios previos en cuanto a las medidas afectadas en este trastorno neurodegenerativo. Sin embargo, las alteraciones observadas deben interpretarse con cautela, dado que la dirección de las diferencias en las medidas puede orientar distintas interpretaciones. Aun así, puesto que la aplicación del análisis de grafos a los datos derivados de neuroimágenes sigue siendo un enfoque muy nuevo (poco más de una década), es demasiado pronto para relacionar los resultados del análisis topológico con la fisiopatología de la DFT. Siendo este es uno de los aspectos que en la actualidad limita el uso de la conectividad, particularmente estructural, en un entorno clínico cotidiano para el diagnóstico de la DFT. De igual manera, los resultados de la presente investigación resaltan otro aspecto a considerar en la utilidad clínica de este enfoque, dado que, como se ha evidenciado al usar diversas herramientas de procesameinto no se encuentran exactamente las mismas alteraciones reportadas previamente (Reyes PA. Biomarkers based on neuroimages to neurodegenerative diseases [Doctoral thesis]. Bogota D.C: Pontificia Universidad Javeriana; 184 p. Forthcoming 2019). La diferencia en la direccionalidad de algunas métricas topológicas respecto al estudio de referencia, no implica que el enfoque tomado carezca de identificación de cambios relevantes en el trastorno neurodegenerativo de la DFT, sino que sugiere desde una perspectiva técnica, la necesidad de un estudio más exhaustivo en relación con las herramientas y software disponibles para el análisis de conectividad estructural, en el que se puedan comparar las diversas aproximaciones, y permita dilucidar qué tan fiables son los resultados de conectividad que se pueden obtener con las tecnologías de procesamiento disponible en la actualidad. Debido a que utilizar líneas de procesamiento alternativas, no se encontraba dentro del alcance de este estudio, se propone la realización de este símil como trabajo futuro.

En general el acercamiento mediante NBS para el análisis de conectividad estructural otorga un mayor grado de precisión en las asociaciones que pueden extraerse entre las regiones cerebrales alteradas y las disfunciones que 
describen las variantes de la demencia frontotemporal. Los pacientes con demencia semántica tienen un extenso daño en estas en comparación con las otras variantes (bvDFT y APP), debido a la elevada cantidad de desconexiones en el lóbulo temporal y que esta se presentó en ambos hemisferios cerebrales. Mientras que la variante comportamental se caracterizó por una pérdida o alteración preferencial interhemisférica centrada en la región frontal del lóbulo derecho. En particular, la bvDFT también se asoció también con afectaciones de lóbulos parietal y occipital, los cuales se ha observado se vuelven disfuncionales más adelante en el curso de la enfermedad $[45,46]$.

Como todo trabajo, el presente estudio no está exento de limitaciones. Se presentan algunas limitaciones relacionadas con el diseño del estudio, como el tamaño de la muestra de pacientes con variantes lingüísticas (DS y APP), el cual fue inferior a bvDFT (menos de la mitad). Sin embargo, este síndrome es de menor prevalencia en la DFT, dificultando la obtención de muestras superiores. Otro aspecto es el relacionado con el diagnóstico clínico, dado que en este estudio los pacientes con DFT fueron diagnosticados por consenso en una clínica de memoria, y no se tuvo acceso a la confirmación patológica. Por otro lado, también se cuenta con algunas limitaciones metodológicas, las cuales podría estar dirigidas al protocolo de adquisición de imágenes de difusión y las matrices de conectividad. Tanto la adquisición como el preprocesamiento pueden alterar el análisis y las métricas obtenidas. Finalmente, se ha mostrado un efecto de escala sobre el análisis de grafos, relacionado con el número de nodos utilizados para la estimación de las matrices de conectividad [47], es decir, la cantidad de regiones cerebrales semilla empleadas, lo que puede dificultar la comparabilidad entre estudios que utilicen diferentes atlas cerebrales.

Investigaciones futuras pueden orientarse a la utilización de enfoques multimodales de imagenología para la exploración de relaciones entre biomarcadores, esto con el fin de esclarecer si los patrones específicos de los cambios estructurales en DFT están asociados con alteraciones específicas de la conectividad funcional. Adicionalmente, como trabajo futuro es interesante la comparación de los hallazgos de la red con otras enfermedades neurodegenerativas, las cuales clínicamente se solapen con los síntomas de DFT, puesto que existe la posibilidad que los diferentes síntomas cognitivos surjan de diferentes tipos de alteraciones de la red. Asimismo, se propone evaluar la capacidad de las métricas topológicas en la clasificación de la DFT y sus variantes, a partir de técnicas de aprendizaje de máquina (clásicas o deep learnnig), debido a que es una herramienta que se encuentra en continuo crecimiento, aceptación e implementación en el campo de la salud.
En Conclusión, los resultados de la presente investigación resaltan como las medidas de conectividad estructural derivadas de dMRI, pueden postularse para la construcción de biomarcadores no invasivos del deterioro en pacientes con DFT y sus variantes. Apoyando el proceso de diagnóstico y la detección oportuna de la enfermedad. Igualmente subrayan la importancia de aplicar el análisis de redes para comprender el papel de la conectividad cerebral en la evolución de la enfermedad.

\section{Agradecimientos}

Las imágenes de resonancia para realizar este estudio fueron facilitadas por la clínica de memoria del Hospital Universitario San Ignacio de la Universidad Javeriana en 2018.

\section{Conflicto DE InTEREses}

Todos los autores declaran no tener ningún conflicto de intereses.

\section{REFERENCIAS}

[1]. WHO | Priority diseases and reasons for inclusion [Internet]. WHO. [cited 2018 Aug 17]. Available from: http://www.who.int/ medicines/areas/priority_medicines/prior_med_ch6_12/en/

[2]. Mahoney CJ, Ridgway GR, Malone IB, Downey LE, Beck J, Kinnunen KM, et al. Profiles of white matter tract pathology in frontotemporal dementia. Hum Brain Mapp. 2014 Aug 1;35(8):4163-79.

[3]. Santillo AF, Mårtensson J, Lindberg O, Nilsson M, Manzouri A, Waldö ML, et al. Diffusion Tensor Tractography versus Volumetric Imaging in the Diagnosis of Behavioral Variant Frontotemporal Dementia. PLOS ONE. 2013 Jul 18;8(7):e66932.

[4]. Fernández-Matarrubia M, Matías-Guiu JA, Moreno-Ramos T, Matías-Guiu J. Biomarkers: a new approach to behavioural variant frontotemporal dementia. Neurología (English Edition). 2015 Jan 1;30(1):50-61.

[5]. Miller BL. Frontotemporal dementia and semantic dementia: anatomic variations on the same disease or distinctive entities? Alzheimer Dis Assoc Disord. 2007 Dec;21(4):S19-22.

[6]. Beach TG, Monsell SE, Phillips LE, Kukull W. Accuracy of the Clinical Diagnosis of Alzheimer Disease at National Institute on Aging Alzheimer Disease Centers, 2005Y2010. J Neuropathol Exp Neurol. 2012;71(4):8.

[7]. Tartaglia MC, Zhang Y, Racine C, Laluz V, Neuhaus J, Chao L, et al. Executive dysfunction in frontotemporal dementia is related to abnormalities in frontal white matter tracts. J Neurol. 2012 Jun;259(6):1071-80.

[8]. Rascovsky K, Hodges JR, Knopman D, Mendez MF, Kramer JH, Neuhaus J, et al. Sensitivity of revised diagnostic criteria for the behavioural variant of frontotemporal dementia. Brain. 2011 Sep 1;134(9):2456-77. 
[9]. Mendez MF, Shapira JS, McMurtray A, Licht E, Miller BL. Accuracy of the Clinical Evaluation for Frontotemporal Dementia. Arch Neurol. 2007 Jun 1;64(6):830-5.

[10]. Knopman DS, Boeve BF, Parisi JE, Dickson DW, Smith GE, Ivnik RJ, et al. Antemortem diagnosis of frontotemporal lobar degeneration. Annals of Neurology. 2005;57(4):480-8.

[11]. Möller C, Hafkemeijer A, Pijnenburg YAL, Rombouts SARB, van der Grond J, Dopper E, et al. Joint assessment of white matter integrity, cortical and subcortical atrophy to distinguish $\mathrm{AD}$ from behavioral variant FTD: A two-center study. Neuroimage Clin. 2015 Sep 9;9:418-29.

[12]. Borroni B, Brambati SM, Agosti C, Gipponi S, Bellelli G, Gasparotti R, et al. Evidence of White Matter Changes on Diffusion Tensor Imaging in Frontotemporal Dementia. Archives of Neurology. 2007 Feb 1;64(2):246.

[13]. Steketee RME, Meijboom R, de Groot M, Bron EE, Niessen WJ, van der Lugt A, et al. Concurrent white and gray matter degeneration of disease-specific networks in early-stage Alzheimer's disease and behavioral variant frontotemporal dementia. Neurobiology of Aging. 2016 Jul 1;43:119-28.

[14]. Sotiropoulos SN, Jbabdi S, Xu J, Andersson JL, Moeller S, Auerbach EJ, et al. Advances in diffusion MRI acquisition and processing in the Human Connectome Project. Neuroimage. 2013 Oct 15;80:125-43.

[15]. Behrens TE, Sporns O. Human connectomics. Current Opinion in Neurobiology. 2012 Feb;22(1):144-53.

[16]. Van Essen DC, Glasser MF. The Human Connectome Project: Progress and Prospects. Cerebrum [Internet]. 2016 Sep 1 [cited 2018 Aug 17];2016. Available from: https://www.ncbi.nlm.nih. gov/pmc/articles/PMC5198757/

[17]. Kaiser M. A tutorial in connectome analysis: Topological and spatial features of brain networks. NeuroImage. 2011 Aug;57(3):892-907.

[18]. Rubinov M, Sporns O. Complex network measures of brain connectivity: Uses and interpretations. NeuroImage. 2010 Sep;52(3):1059-69.

[19]. Agosta F, Sala S, Valsasina P, Meani A, Canu E, Magnani G, et al. Brain network connectivity assessed using graph theory in frontotemporal dementia. Neurology. 2013 Jul 9;81(2):134-43.

[20]. Reyes P, Ortega-Merchan MP, Rueda A, Uriza F, SantamariaGarcía H, Rojas-Serrano N, et al. Functional Connectivity Changes in Behavioral, Semantic, and Nonfluent Variants of Frontotemporal Dementia. Behav Neurol [Internet]. 2018 Apr 1 [cited 2019 Feb 17];2018. Available from: https://www.ncbi.nlm. nih.gov/pmc/articles/PMC5902123/

[21]. Sedeño L, Couto B, García-Cordero I, Melloni M, Baez S, Morales Sepúlveda JP, et al. Brain Network Organization and Social Executive Performance in Frontotemporal Dementia. Journal of the International Neuropsychological Society. 2016 Feb;22(02):250-62.

[22]. Yu M, Gouw AA, Hillebrand A, Tijms BM, Stam CJ, van Straaten $\mathrm{ECW}$, et al. Different functional connectivity and network topology in behavioral variant of frontotemporal dementia and Alzheimer's disease: an EEG study. Neurobiology of Aging. 2016 Jun;42:150-62.

[23]. Jenkinson M, Beckmann CF, Behrens TEJ, Woolrich MW, Smith SM. FSL. NeuroImage. 2012 Aug;62(2):782-90.
[24]. Jones DK, Simmons A, Williams SCR, Horsfield MA. Noninvasive assessment of axonal fiber connectivity in the human brain via diffusion tensor MRI. Magnetic Resonance in Medicine. 1999;42(1):37-41.

[25]. Fan L, Li H, Zhuo J, Zhang Y, Wang J, Chen L, et al. The Human Brainnetome Atlas: A New Brain Atlas Based on Connectional Architecture. Cereb Cortex. 2016 Aug 1;26(8):3508-26.

[26]. Griffa A, Baumann PS, Thiran J-P, Hagmann P. Structural connectomics in brain diseases. NeuroImage. 2013 Oct;80:515-26.

[27]. Fornito A, Zalesky A, Bullmore E. Fundamentals of Brain Network Analysis. Academic Press; 2016. 496 p.

[28]. Sporns O. Networks of the Brain. MIT Press; 2010. 433 p.

[29]. Sporns O. From simple graphs to the connectome: Networks in neuroimaging. NeuroImage. 2012 Aug 15;62(2):881-6.

[30]. Bullmore E, Sporns O. Complex brain networks: graph theoretical analysis of structural and functional systems. Nat Rev Neurosci. 2009 Mar;10(3):186-98.

[31]. [31]. Zalesky A, Fornito A, Bullmore ET. Network-based statistic: Identifying differences in brain networks. NeuroImage. 2010 Dec 1;53(4):1197-207.

[32]. Xia M, Wang J, He Y. BrainNet Viewer: A Network Visualization Tool for Human Brain Connectomics. PLOS ONE. $2013 \mathrm{Jul}$ 4;8(7):e68910.

[33]. Filippi M, Agosta F, Scola E, Canu E, Magnani G, Marcone A, et al. Functional network connectivity in the behavioral variant of frontotemporal dementia. Cortex. 2013 Oct 1;49(9):2389-401.

[34]. Andreotti J, Dierks T, Wahlund L-O, Grieder M. Diverging Progression of Network Disruption and Atrophy in Alzheimer's Disease and Semantic Dementia. J Alzheimers Dis. 55(3):981-93.

[35]. de Haan W, Pijnenburg YA, Strijers RL, van der Made Y, van der Flier WM, Scheltens $P$, et al. Functional neural network analysis in frontotemporal dementia and Alzheimer's disease using EEG and graph theory. BMC Neuroscience. 2009 Aug 21;10(1):101.

[36]. Hafkemeijer A, Möller C, Dopper E, Jiskoot L, van den BergHuijsmans A, van Swieten J, et al. A Longitudinal Study on Resting State Functional Connectivity in Behavioral Variant Frontotemporal Dementia and Alzheimer's Disease. Journal of Alzheimer's Disease. 2017 Jan 1;55(2):521-37.

[37]. Hafkemeijer A, Möller C, Dopper EGP, Jiskoot LC, Schouten $\mathrm{TM}$, Swieten V, et al. Resting state functional connectivity differences between behavioral variant frontotemporal dementia and Alzheimer's disease. Front Hum Neurosci [Internet]. 2015 [cited 2018 Feb 12];9. Available from: https://www.frontiersin. org/articles/10.3389/fnhum.2015.00474/full

[38]. Zhang Y, Schuff N, Du A-T, Rosen HJ, Kramer JH, GornoTempini ML, et al. White matter damage in frontotemporal dementia and Alzheimer's disease measured by diffusion MRI. Brain. 2009 Sep 1;132(9):2579-92.

[39]. Matsuo K, Mizuno T, Yamada K, Akazawa K, Kasai T, Kondo M, et al. Cerebral white matter damage in frontotemporal dementia assessed by diffusion tensor tractography. Neuroradiology. 2008 Jul;50(7):605-11.

[40]. Farb NAS, Grady CL, Strother S, Tang-Wai DF, Masellis M, Black S, et al. Abnormal network connectivity in frontotemporal dementia: Evidence for prefrontal isolation. Cortex. $2013 \mathrm{Jul}$ 1;49(7):1856-73. 
[41]. Hoffmann M. The Human Frontal Lobes and Frontal Network Systems: An Evolutionary, Clinical, and Treatment Perspective [Internet]. International Scholarly Research Notices. 2013 [cited 2019 Mar 12]. Available from: https://www.hindawi.com/ journals/isrn/2013/892459/

[42]. Booth JR, Wood L, Lu D, Houk JC, Bitan T. The role of the basal ganglia and cerebellum in language processing. Brain Res. 2007 Feb 16;1133(1):136-44.

[43]. Kotz SA, Frisch S, Cramon DYV, Friederici AD. Syntactic language processing: ERP lesion data on the role of the basal ganglia. Journal of the International Neuropsychological Society. 2003 Nov;9(7):1053-60.

[44]. Tyler LK, Marslen-Wilson WD, Randall B, Wright P, Devereux BJ, Zhuang J, et al. Left inferior frontal cortex and syntax: function, structure and behaviour in patients with left hemisphere damage. Brain. $2011 \mathrm{Feb} ; 134(2): 415-31$.

[45]. Brambati SM, Renda NC, Rankin KP, Rosen HJ, Seeley WW, Ashburner J, et al. A tensor based morphometry study of longitudinal gray matter contraction in FTD. Neuroimage. 2007 Apr 15;35(3):998-1003.
[46]. Seeley WW, Crawford R, Rascovsky K, Kramer JH, Weiner M, Miller BL, et al. Frontal Paralimbic Network Atrophy in Very Mild Behavioral Variant Frontotemporal Dementia. Arch Neurol. 2008 Feb;65(2):249-55.

[47]. Zalesky A, Fornito A, Harding IH, Cocchi L, Yücel M, Pantelis C, et al. Whole-brain anatomical networks: does the choice of nodes matter? Neuroimage. 2010 Apr 15;50(3):970-83.

\section{Material Suplementario}

Variación de las medidas topológicas extraidas en función del umbral. Los valores corresponden al promedio de dicha métrica para cada uno de los grupos (sujetos sanos y las 3 variantes de DFT). Se muestra adicionlmente el valor de la conectancia o densidad de conexión de la red, el cual muestra como se reduce considerablemente las conexiones en la matriz cuando se eliminan los valores cercanos a cero, los cuales son considerados de representar conexiones falsopositivos. DS: demencia semántica; APP: afasia progresiva primaria; bvDFT : variante comportamental de DFT.

\section{Métricas topológicas en función del umbral}
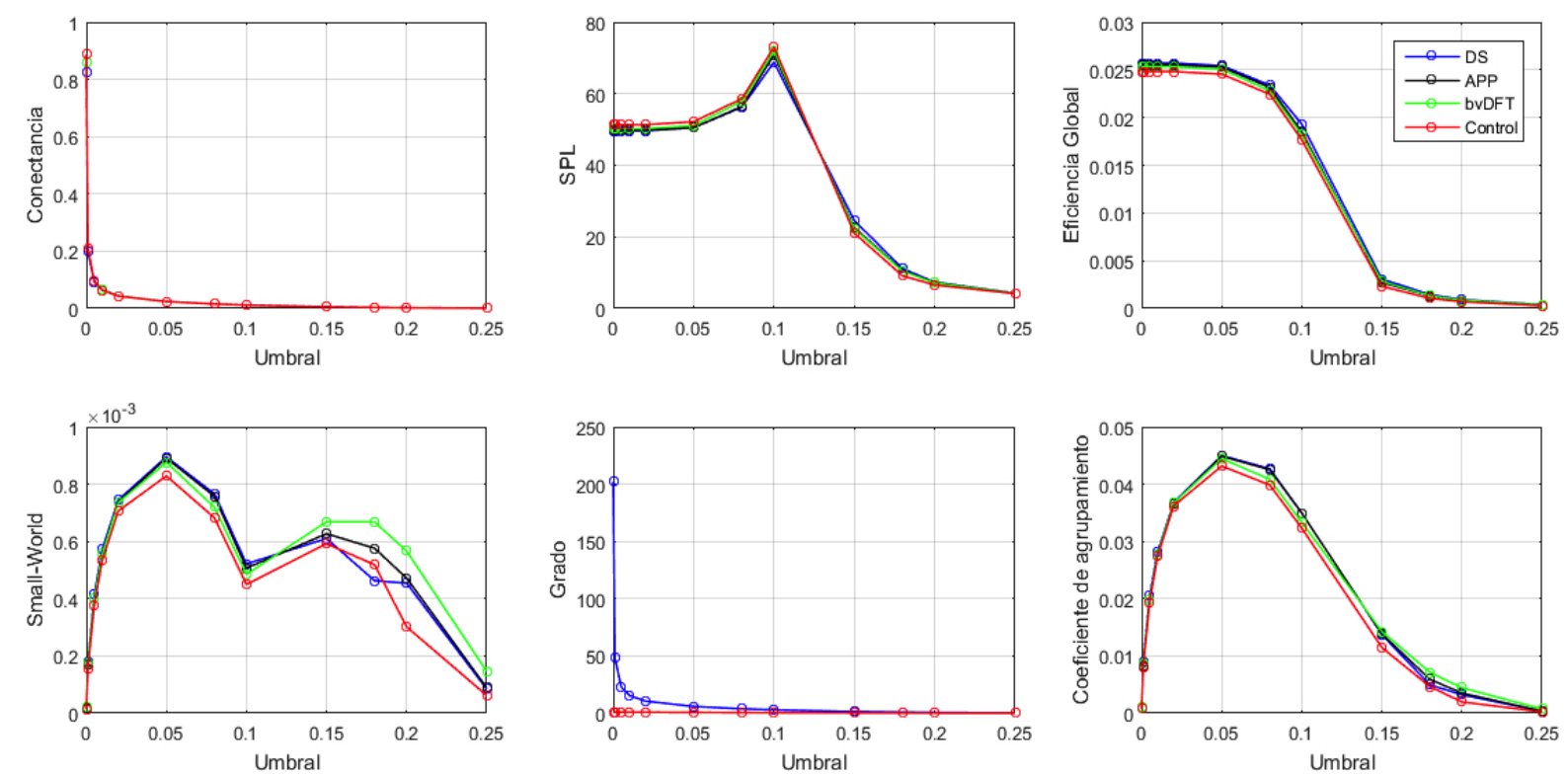